\title{
Effectiveness of pharmacist dosing adjustment for critically ill patients receiving continuous renal replacement therapy: a comparative study
}

This article was published in the following Dove Press journal:

Therapeutics and Clinical Risk Management

3 June 2014

Number of times this article has been viewed

\author{
Sai-Ping Jiang' \\ Zheng-Yi Zhu ${ }^{2}$ \\ Xiao-Liang $\mathrm{Wu}^{3}$ \\ Xiao-Yang Lu' \\ Xing-Guo Zhang' \\ Bao-Hua $\mathrm{Wu}^{\prime}$
}

'Department of Pharmacy, the First Affiliated Hospital, ${ }^{2}$ Department of Pharmacy, Children's Hospital, College of Medicine, Zhejiang University, Hangzhou, ${ }^{3}$ Intensive Care Unit, the First Affiliated Hospital, College of Medicine, Zhejiang University, Hangzhou, People's Republic of China

Correspondence: Bao-Hua Wu Department of Pharmacy, the First Affiliated Hospital, College of Medicine, Zhejiang University, 79 Qingchun Road, Hangzhou, 3 I0003, People's Republic of China

$\mathrm{Tel} / \mathrm{Fax}+8657$ I 872334 II

Email j5145@sina.com
Background: The impact of continuous renal replacement therapy (CRRT) on drug removal is complicated; pharmacist dosing adjustment for these patients may be advantageous. This study aims to describe the development and implementation of pharmacist dosing adjustment for critically ill patients receiving CRRT and to examine the effectiveness of pharmacist interventions.

Methods: A comparative study was conducted in an intensive care unit (ICU) of a universityaffiliated hospital. Patients receiving CRRT in the intervention group received specialized pharmacy dosing service from pharmacists, whereas patients in the no-intervention group received routine medical care without pharmacist involvement. The two phases were compared to evaluate the outcome of pharmacist dosing adjustment.

Results: The pharmacist carried out 233 dosing adjustment recommendations for patients receiving CRRT, and 212 (90.98\%) of the recommendations were well accepted by the physicians. Changes in CRRT-related variables ( $\mathrm{n}=144,61.81 \%$ ) were the most common risk factors for dosing errors, whereas antibiotics $(n=168,72.10 \%)$ were the medications most commonly associated with dosing errors. Pharmacist dosing adjustment resulted in a US\$2,345.98 ICU cost savings per critically ill patient receiving CRRT. Suspected adverse drug events in the intervention group were significantly lower than those in the preintervention group (35 in 27 patients versus [vs] 18 in eleven patients, $P<0.001)$. However, there was no significant difference between length of ICU stay and mortality after pharmacist dosing adjustment, which was 8.93 days vs 7.68 days $(P=0.26)$ and $30.10 \%$ vs $27.36 \%(P=0.39)$, respectively.

Conclusion: Pharmacist dosing adjustment for patients receiving CRRT was well accepted by physicians, and was related with lower adverse drug event rates and ICU cost savings. These results may support the development of strategies to include a pharmacist in the multidisciplinary ICU team.

Keywords: pharmacist interventions, drug dosing adjustment, adverse drug event, cost saving, CRRT

\section{Introduction}

Continuous renal replacement therapy (CRRT) is better tolerated by hemodynamically unstable patients ${ }^{1}$ in intensive care units (ICUs). It is frequently used for patients who are most unstable regardless if the insult is acute (ie, acute kidney injury) or in those with chronic renal failure. Several methods of CRRT currently exist, but the most common modalities used in ICUs are continuous venovenous hemofiltration, continuous venovenous hemodialysis, and continuous venovenous hemodialfiltration. ${ }^{2}$

CRRT provides considerable benefits to critically ill patients through gentle removal of excess metabolic waste products and the return of normal electrolyte and 
acid/base balance, ${ }^{3}$ but it can also cause alterations in drug clearance. Drugs predominantly eliminated by the kidneys often undergo substantial removal during CRRT. ${ }^{4}$ Factors that influence plasma drug concentration during CRRT include the drug properties, mode of CRRT, and the severity of illness related to residual renal function and liver function. ${ }^{4}$ Moreover, a patient may undergo different modalities (diffusion, convection, or both) as well as changes in blood and ultrafiltration flows, and the prescribed dose can differ from the current dose during the ICU stay. ${ }^{5}$ For these reasons, pharmacokinetics for critically ill patients receiving CRRT are complicated, and drug dosing adjustment is essential.

Pharmacist dosing adjustment for patients receiving CRRT may be advantageous, but no prior studies were found on the topic. In this study, the drug dosage of patients receiving CRRT was adjusted by an ICU clinical pharmacist who specializes in dosing adjustment for such patients. The purpose was to introduce and evaluate the pharmacist dosing adjustment process and subsequent outcomes. This article discusses: 1) the type of dosing adjustments the pharmacist carried out, 2) whether specialized dosing adjustments for patients receiving CRRT were well accepted by physicians, and 3 ) the additional value the pharmacist brought through full-time dosing adjustment for patients receiving CRRT, such as influence on drug and ICU hospitalization cost, length of ICU stay, and mortality in ICU.

\section{Materials and methods}

\section{Setting}

This study was carried out in the medical and surgical ICU of The First Hospital, College of Medicine, Zhejiang University, Hangzhou, People's Republic of China. The medical staff of the closed-format, 33-bed ICU consisted of state-certified intensivists, ICU fellows and residents, registered nurses, respiratory therapists, a full-time critical care pharmacist, and two pharmacy residents. CRRT was routinely conducted by a CRRT group with kidney disease physicians. CRRT was mainly performed by means of continuous venovenous hemofiltration using a PrismaFlex machine (Hospal, Meyzieu, France) with an AN69 hemofilter (PrismaFlex M100 set). The ultrafiltration rate was set at a range of 1,500-3,000 mL/hour in predilution mode.

\section{Study design and patients}

A single-centered, two-phased (intervention/No-intervention) design was conducted. The no-intervention phase was carried out between July 2011 and December 2011 (184 days). A total of 103 patients receiving CRRT were treated without involv- ing pharmacists for drug dosing adjustment; these patients provided baseline information before pharmacist intervention. The intervention phase was carried out between January 2012 and June 2012 (181 days). A total of 106 patients receiving CRRT were subjected to specialized pharmacy dosing follow-up by a full-time, experienced pharmacist and two pharmacy residents in the ICU. These patients formed the intervention group.

Patients were included in the study if they were admitted to the ICU, diagnosed with acute kidney injury or chronic renal failure, received CRRT, and were $\geq 18$ years old. Patients were excluded if they did not meet all the aforementioned inclusion criteria. Ethical approval was obtained from the Research Review Committee of the hospital.

\section{Pharmacist drug dosing adjustment}

The pharmacist and pharmacist residents completed 2 weeks of training before the study was started. The training included reviewing all pertinent literature, completing patient assessments, and reviewing eligible patients with the present authors. During the intervention period, the pharmacists assessed the patients receiving CRRT daily during ICU rounds, and then made dosage adjustment interventions when needed. Patients who were not seen during ICU rounds were assessed after the rounds, and recommendations were made to physicians and nurses at that time. All interventions made by the pharmacist were verbal and recorded in a specially designed pharmacist intervention form. This form included the following patient details: baseline demographic characteristics (sex, age, and diagnosis), renal function, mode of CRRT, blood flow rate, ultrafiltration rate, length of CRRT time per day, dosage adjustment recommendations, and the acceptance of recommendations. An acceptance rate greater than $80 \%$ was considered well accepted by physicians.

Dosing adjustments for patients receiving CRRT are complicated because of the heterogeneity among individual patients and the absence of practice guidelines. To overcome this problem, we either adjusted the drug dosage based on therapeutic drug monitoring or made a pocket-sized card (Table 1) for the clinical pharmacist during rounds. The pocket-sized card contained the dosing adjustment recommendations for patients receiving CRRT according to reliable and current literature. ${ }^{2,4,6-10}$ These recommendations were reviewed and approved by a professor of clinical pharmacy and a senior ICU specialist before the intervention phase was started. The dosing adjustment also considered the following factors ${ }^{11}$ that influenced drug elimination during the pharmacy dosing follow-up process: 1) patient-related variables, namely protein 
Table I Recommended drug dosing in critically ill patients receiving continuous renal replacement therapy

\begin{tabular}{|c|c|c|c|}
\hline \multirow[t]{2}{*}{ Drugs } & \multicolumn{3}{|c|}{ Dosing recommendations based on ultrafiltration rate ${ }^{a}$} \\
\hline & I,500 mL/h & $2,000-2,500 \mathrm{~mL} / \mathrm{h}$ & $3,000 \mathrm{~mL} / \mathrm{h}$ \\
\hline \multicolumn{4}{|c|}{ Drugs eliminated primarily via renal clearance } \\
\hline Ceftazidime $^{2,7}$ & I g every $6 \mathrm{~h}$ & $2 \mathrm{~g}$ every $8 \mathrm{~h}$ & 2 g every $8 \mathrm{~h}$ \\
\hline Ceftriaxone ${ }^{2}$ & 2 g every $12-24 \mathrm{~h}$ & $2 \mathrm{~g}$ every $\mathrm{I} 2-24 \mathrm{~h}$ & $2 \mathrm{~g}$ every $12-24 \mathrm{~h}$ \\
\hline Cefoperazone-sulbactam ${ }^{\mathrm{b}}$ & $\mathrm{I}-2 \mathrm{~g}$ every $6 \mathrm{~h}$ & I-2 g every $6 \mathrm{~h}$ & $2 \mathrm{~g}$ every $6 \mathrm{~h}$ \\
\hline Cefepime $^{8}$ & I g every $8 \mathrm{~h}$ & I g every $6 \mathrm{~h}$ & I g every $6 \mathrm{~h}$ \\
\hline Piperacillin-tazobactam ${ }^{2,7, c}$ & $3.375 \mathrm{~g}$ every $6 \mathrm{~h}$ & $4.5 \mathrm{~g}$ every $6 \mathrm{~h}$ & $4.5 \mathrm{~g}$ every $6 \mathrm{~h}$ \\
\hline Imipenem-cilastatin ${ }^{2, d}$ & $0.5 \mathrm{~g}$ every $8 \mathrm{~h}$ & $0.5 \mathrm{~g}$ every $6 \mathrm{~h}$ & $0.5 \mathrm{~g}$ every $6 \mathrm{~h}$ \\
\hline Meropenem ${ }^{2,7}$ & $0.5 \mathrm{~g}$ every $6 \mathrm{~h}$ & I g every $8 \mathrm{~h}$ & I g every $8 \mathrm{~h}$ \\
\hline Vancomycine & 15 mg/kg LD+ & 15 mg/kg LD+ & 15 mg/kg LD+ \\
\hline \multirow[t]{2}{*}{ Teicoplanin ${ }^{4}$} & $\mathrm{LD}+1,200 \mathrm{mg}$ & $\mathrm{LD}+\mathrm{I}, 200 \mathrm{mg}$ & LD I,200 mg \\
\hline & $600-1,800 \mathrm{mg}$ once daily & $600-1,800 \mathrm{mg}$ once daily & $600-1,800 \mathrm{mg}$ once daily \\
\hline \multirow[t]{2}{*}{ Levofloxacin ${ }^{2}$} & $500 \mathrm{mg} \mathrm{LD}{ }^{+}$ & $500 \mathrm{mg} \mathrm{LD}+$ & $500 \mathrm{mg}$ every $24 \mathrm{~h}$ \\
\hline & $250 \mathrm{mg}$ every $24 \mathrm{~h}$ & $250 \mathrm{mg}$ every $24 \mathrm{~h}$ & \\
\hline $\operatorname{Amikacin}^{2, e}$ & 10 mg/kg LD+ & $10 \mathrm{mg} / \mathrm{kg} \mathrm{LD}^{+}$ & $10 \mathrm{mg} / \mathrm{kg} \mathrm{LD}{ }^{+}$ \\
\hline Linezolid $^{2}$ & $600 \mathrm{mg}$ every $12 \mathrm{~h}$ & $600 \mathrm{mg}$ every $12 \mathrm{~h}$ & $600 \mathrm{mg}$ every $12 \mathrm{~h}$ \\
\hline Fosfomycin ${ }^{6}$ & $4 \mathrm{~g}$ every $6 \mathrm{~h}$ & $4 \mathrm{~g}$ every $6 \mathrm{~h}$ & $4 \mathrm{~g}$ every $6 \mathrm{~h}$ \\
\hline Fluconazole ${ }^{2}$ & $200-400 \mathrm{mg}$ every $24 \mathrm{~h}$ & $400-800 \mathrm{mg}$ every $24 \mathrm{~h}$ & $400-800 \mathrm{mg}$ every $24 \mathrm{~h}$ \\
\hline Sodium chloride & \multirow{3}{*}{\multicolumn{3}{|c|}{ Dosing adjustment according to the lab test or serum drug concentration }} \\
\hline Potassium chloride & & & \\
\hline Digoxin $^{e}$ & & & \\
\hline \multicolumn{4}{|c|}{ Drugs eliminated primarily via nonrenal clearance ${ }^{\mathrm{f}, g}$} \\
\hline \multicolumn{4}{|c|}{$\begin{array}{l}\text { Voriconazole, caspofungin, amphotericin B, moxifloxacin, metronidazole, heparin, }{ }^{\mathrm{h}} \text { omeprazole, midazolam, } \text { propofol,' amiodarone, warfarin, }{ }^{\mathrm{i}} \\
\text { aminophylline, etc }\end{array}$} \\
\hline
\end{tabular}

Notes: Special consideration: If CRRT system is discontinued or switched to another mode of renal replacement therapy, dosages should be adjusted to the patient's intrinsic renal function or to the new mode of renal replacement therapy. ${ }^{a} \mathrm{lt}$ is assumed that patients have normal hepatic function and are anuric; bavailable commercially in a fixed ratio of $500 \mathrm{mg}$ to $500 \mathrm{mg}$; 'available commercially in a fixed ratio of $4 \mathrm{~g}$ to $0.5 \mathrm{~g}$; davailable commercially in a fixed ratio of $250 \mathrm{mg}$ to $250 \mathrm{mg}$; ${ }^{\mathrm{e}}$ serum drug concentrations should be monitored (trough level: vancomycin $10-15 \mathrm{mg} / \mathrm{mL}$; amikacin $5-10 \mathrm{mg} / \mathrm{mL}$; digoxin 0.8-2.0 ng/mL; aminophylline); the renal clearance of a drug is less than

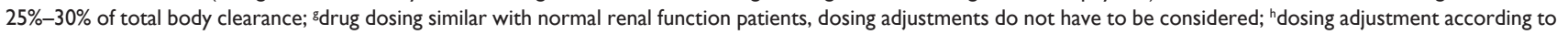
activated partial thromboplastin time; 'dosing adjustment according to Ramsay sedation scale; idosing adjustment according to international normalized ratio.

Abbreviations: CRRT, continuous renal replacement therapy; h, hours; LD+, loading dose.

level, volume of distribution, residual renal function, and liver function; 2) CRRT-related variables, namely mode of CRRT, blood flow rate, ultrafiltration rate, and length of CRRT time per day; and 3) drug-related variables, namely molecular weight of drug, protein binding, and degree of renal clearance.

\section{Outcome measurement and definitions}

At the end of the study, the no-intervention and intervention groups were compared to evaluate the outcomes of pharmacist interventions; the variables compared included length of ICU stay, mortality in ICU, ICU drug and hospitalization costs per admission, and the occurrence of adverse drug events (ADEs). Length of ICU stay refers to the number of days in the ICU from admission to discharge. ICU hospitalization cost is defined as all costs in the ICU, including the costs of drugs, examinations, nursing care, and pharmacist care (postintervention phase). Costs in Chinese currency were converted to US dollars (exchange rate, 6.3 Yuan $=\$ 1$ US).

ADEs were evaluated according to preventability, causality, and severity. Preventable ADEs were defined as any injury associated with medication errors. ${ }^{12,13}$ The Naranjo algorithm ${ }^{14}$ was used to assess the causal relationship between the suspected drug and the event. The seriousness of ADEs was evaluated based on the definition of the State Food and Drug Administration. Serious ADEs are those that "result in death, a life-threatening condition, initial or extended hospitalization, persistent or significant disability, cancer, and congenital abnormalities." ADEs that did not meet this definition but still required treatment were defined as significant. Events that did not require treatment were defined as mild or nonsignificant. ${ }^{12,13}$

\section{Data collection and statistical analysis}

After patient discharge, all patient medical records from both phases were reviewed by an ICU specialist and a pharmacist resident, both of whom were blinded to the patients' allocation status. The recorded data included the following patient details: baseline characteristics such as admission diagnosis, sex, age, weight, renal function, and Acute Physiology and Chronic Health Evaluation II (APACHE II) scores; ${ }^{15}$ length 
of CRRT; length of ICU stay; death in the ICU; number of drugs used in the ICU; drug costs; ICU hospitalization costs; and occurrence of ADEs. Any ADE issue detected was discussed by the ICU specialist and the pharmacist; if a consensus was reached, the issue was considered an ADE.

All collected data were entered into the statistical analysis software (SPSSC Version 19.0; IBM Corporation, Armonk, NY, USA) for analysis. Comparisons between the pre- and postintervention phases with regard to patient characteristics, APACHE II scores, and admission creatinine and urea concentrations were made by Student's $t$-test for continuous variables, nonparametric Mann-Whitney U test for non-normal distribution values, and chi-squared test for categorical data. $P<0.05$ was considered statistically significant.

\section{Results}

\section{Patient characteristics}

Table 2 shows the patient characteristics of each group. The two groups were well matched in terms of age, sex, weight, APACHE II scores, number of drugs used in the ICU, admission diagnosis,

Table 2 Patient characteristics

\begin{tabular}{|c|c|c|c|}
\hline Parameter & No-intervention & Intervention & $P$ value \\
\hline Patients, $n$ & 103 & 106 & 0.61 \\
\hline Male & 57 & 61 & \\
\hline Female & 46 & 45 & \\
\hline Age, years & $61.3 \pm 16.9$ & $58.9 \pm 17.3$ & 0.28 \\
\hline Weight, kg & $63.4 \pm 19.7$ & $59.6 \pm 21.3$ & 0.42 \\
\hline APACHE II score ${ }^{15}$ & $22.8 \pm 8.9$ & $21.4 \pm 10.2$ & 0.73 \\
\hline $\begin{array}{l}\text { Admission creatinine } \\
\text { concentration, } \mathrm{mmol} / \mathrm{L}\end{array}$ & $260.44 \pm 119.78$ & $267.11 \pm 109.99$ & 0.44 \\
\hline $\begin{array}{l}\text { Admission urea } \\
\text { concentration, } \mathrm{mmol} / \mathrm{L}\end{array}$ & $22.53 \pm 12.19$ & $21.78 \pm 8.57$ & 0.30 \\
\hline \multicolumn{4}{|c|}{ Admission diagnosis, n (\%) } \\
\hline $\begin{array}{l}\text { Pneumonia and/or } \\
\text { ARDS }\end{array}$ & $23(22.81)$ & $25(23.58)$ & 0.39 \\
\hline Septic shock & $20(19.30)$ & $17(16.04)$ & 0.41 \\
\hline $\begin{array}{l}\text { CHF/pulmonary } \\
\text { edema }\end{array}$ & $18(17.54)$ & $2 I(\mid 9,8 I)$ & 0.38 \\
\hline $\begin{array}{l}\text { Cardiac/aortic } \\
\text { surgery }\end{array}$ & $9(8.77)$ & $7(6.60)$ & 0.48 \\
\hline $\begin{array}{l}\text { Gastrointestinal } \\
\text { surgery }\end{array}$ & $9(8.77)$ & $15(14.15)$ & 0.17 \\
\hline MODS & $14(14.04)$ & $9(8.49)$ & 0.21 \\
\hline Others $^{\mathrm{a}}$ & $23(22.8 \mathrm{I})$ & 27 (25.47) & 0.31 \\
\hline $\begin{array}{l}\text { Length of CRRT } \\
\text { treatment, } \mathrm{h}\end{array}$ & $91.13 \pm 89.52$ & $85.92 \pm 96.96$ & 0.28 \\
\hline Drugs used in ICU, $\mathrm{n}$ & $9.18 \pm 3.7$ & $9.92 \pm 4.18$ & 0.41 \\
\hline
\end{tabular}

Notes: Data are expressed as $\mathrm{n}(\%)$ or mean \pm standard deviation. Including cerebrovascular accident, trauma, severe pancreatitis, hyperkalemia, and hypercalcemia. Abbreviations: ARDS, adult respiratory distress syndrome; $\mathrm{CHF}$, congestive heart failure; CRRT, continuous renal replacement therapy; h, hours; ICU, intensive care unit; MODS, multiple organ dysfunction syndrome; n, number; APACHE II: Acute Physiology and Chronic Health Evaluation II. and creatinine and urea concentrations $(P>0.05)$. Patients in both groups received about $85-95$ hours of CRRT therapy on average (91.13 hours versus [vs] 85.92 hours, $P=0.28$ ).

\section{Implementation of pharmacist dosing adjustment}

Pharmacist dosing adjustment recommendations were recorded in the intervention group and categorized as follows: incorrect loading dose $(23,9.87 \%)$, incorrect maintenance dose for patients receiving CRRT 24 hours a day $(41,17.59 \%)$, unchanged dosing or incorrect dosing adjustment when CRRT was converted from 24 hours a day to less than 24 hours a day $(73,31.33 \%)$, unchanged dosing or incorrect dosing adjustment when the CRRT mode was changed (9, 3.86\%), unchanged dosing or incorrect dosing adjustment when the ultrafiltrate rate was changed (12, 5.15\%), unchanged dosing or incorrect dosing adjustment when CRRT was changed to intermittent hemodialysis (IHD) or peritoneal dialysis (PD) (17,9.29\%), unchanged dosing or incorrect dosing adjustment when CRRT was discontinued (33, 14.16\%), and drug dosing without consideration of residual renal function $(25,10.73 \%)$. The pharmacist made 233 dosing adjustment recommendations for the 106 patients in the intervention group, and 212 (90.98\%) of these recommendations were accepted by the physicians; thus, the recommendations were considered to be well accepted. The most common reason for pharmacist dosing adjustment was when CRRT was converted from 24 hours a day to less than 24 hours a day $(73,31.33 \%)$. A typical example was that of piperacillin/tazobactam, which was still prescribed as $4.5 \mathrm{~g}$ every 6 hours even when the CRRT length was switched from 24 hours to 12 hours daily.

\section{Analysis of drugs related with dosing errors}

Table 3 shows the types of drug most frequently involved in dosing errors. Antibiotics were the most common drug to be misdosed $(168,72.10 \%)$ in the intervention group, followed by electrolytes $(23,9.87 \%)$, sedatives $(13,5.58 \%)$, antifungals (11, 4.72\%) and cardiovascular medications ( 9 , $3.86 \%)$. Among the medications implemented by pharmacist dosing adjustment, $72.10 \%$ of them were mainly eliminated by the kidneys; the other $27.90 \%$ were cleared via hepatic or other metabolic pathways.

\section{Outcomes of pharmacist interventions}

Table 4 presents the clinical and economic outcomes after pharmacist dosing adjustment for patients receiving CRRT. There was no significant difference in the length of ICU stay 
Table 3 Type of drugs with most dosing errors

\begin{tabular}{|c|c|c|}
\hline Drugs & $\begin{array}{l}\text { Primary route } \\
\text { of elimination }\end{array}$ & n (\%) \\
\hline Antibiotics & & $168(72.10)$ \\
\hline Ceftriaxone & Hepatic & $4(1.72)$ \\
\hline Ceftazidime & Renal & $6(2.56)$ \\
\hline Cefepime & Renal & $10(4.29)$ \\
\hline Cefoperazone-sulbactam & Hepatic/renal & $25(10.73)$ \\
\hline Piperacillin- tazobactam & Renal/renal & $30(12.88)$ \\
\hline Imipenem-cilastatin & Renal/renal & $14(6.01)$ \\
\hline Meropenem & Renal & $16(6.87)$ \\
\hline Vancomycin & Renal & $24(10.30)$ \\
\hline Teicoplanin & Renal & $15(6.44)$ \\
\hline Levofloxacin & Renal & $9(3.86)$ \\
\hline Amikacin & Renal & I $(0.43)$ \\
\hline Linezolid & Hepatic & $8(3.43)$ \\
\hline Fosfomycin & Renal & $6(2.58)$ \\
\hline Electrolytes & & $23(9.87)$ \\
\hline Sodium chloride & Renal & $7(3.00)$ \\
\hline Potassium chloride & Renal & II (4.72) \\
\hline Calcium chloride & Renal & $5(2.15)$ \\
\hline Sedatives & & $13(5.58)$ \\
\hline Midazolam & Hepatic & $7(3.00)$ \\
\hline Propofol & Hepatic & $6(2.58)$ \\
\hline Antifungals & & II (4.72) \\
\hline Fluconazole & Renal & $6(2.58)$ \\
\hline Voriconazole & Hepatic & $2(0.86)$ \\
\hline Caspofungin & Hepatic & $2(0.86)$ \\
\hline Amphotericin B (liposomal) & Unknown & I $(0.43)$ \\
\hline Cardiovascular medications & & $9(3.86)$ \\
\hline Digoxin & Renal & $4(1.72)$ \\
\hline Heparin & Hepatic & $2(0.86)$ \\
\hline Low molecular heparin & Renal & $3(1.29)$ \\
\hline Other medications & & $9(3.86)$ \\
\hline Omeprazole & Hepatic & $4(1.72)$ \\
\hline Aminophylline & Hepatic & $4(1.72)$ \\
\hline Aciclovir & Renal & I (0.43) \\
\hline Total & & $233(100)$ \\
\hline
\end{tabular}

Abbreviation: $\mathrm{n}$, number.

Table 4 Clinical and economic outcomes after pharmacist dosing adjustment for critically ill patients receiving CRRT

\begin{tabular}{|c|c|c|c|}
\hline Parameter & No-intervention & Intervention & $P$ value \\
\hline Mortality, n (\%) & $31(30.10)$ & $29(27.36)$ & 0.39 \\
\hline \multicolumn{4}{|c|}{ Length of ICU stay, days } \\
\hline Mean (SD) & $8.93 \pm 8.96$ & $7.68 \pm 7.63$ & 0.26 \\
\hline Median & 8.1 & 7.3 & \\
\hline \multicolumn{4}{|c|}{ Antibiotics cost, \$US/case } \\
\hline Mean (SD) & $2,321.09 \pm 1,453.52$ & $I, 531.30 \pm I, 092.36$ & 0.013 \\
\hline Median & $\mathrm{I}, 934.58$ & I,354.37 & \\
\hline \multicolumn{4}{|c|}{ Drug cost, $* \$ U S /$ case } \\
\hline Mean (SD) & $3,935.94 \pm 3,790.63$ & $2,7|0.47 \pm 2,773.8|$ & 0.026 \\
\hline Median & $3,062.70$ & I,87I.82 & \\
\hline \multicolumn{4}{|c|}{ ICU hospitalization cost } \\
\hline Mean (SD) & $|0,462.53 \pm 9,004.4|$ & $8,116.55 \pm 8,959.2$ & 0.031 \\
\hline Median & $8,419.68$ & $6,932.85$ & \\
\hline
\end{tabular}

Note: *Including antibiotics and other drug costs.

Abbreviations: \$US, US dollars; CRRT, continuous renal replacement therapy; $\mathrm{ICU}$, intensive care unit; $\mathrm{n}$, number; SD, standard deviation. and mortality in ICU between the no-intervention group and the intervention group (8.93 days vs 7.68 days $[P=0.26]$ on average; $30.10 \%$ vs $27.36 \%$ [ $P=0.39]$, respectively). However, pharmacist dosing adjustment resulted in drug cost savings of $31.1 \%$ per patient without affecting length of stay or mortality, from $\$ 3,935.94$ to $\$ 2,710.47$ ( $P=0.026)$, and antibiotics accounted for $64.47 \%$ of all drug cost savings, which was about $\$ 789.79$ savings per patient (from $\$ 2,321.09$ to $\$ 1,531.30, P=0.013)$. Table 5 also shows the ICU hospitalization cost savings. The presence of an ICU pharmacist resulted in $\$ 2,345.98$ (from $\$ 10,462.53$ to $\$ 8,116.55$, $P=0.031$ ) savings per patient receiving CRRT. Given that the study lasted for 1 year and a total of 209 patients (103 patients in the no-intervention group and 106 patients in the intervention group) receiving CRRT were subjected to pharmacist dosing adjustment, the possible savings for all patients in 1 year can be estimated to be around $\$ 490,309.82$.

Table 5 illustrates that among the 103 patients in the no-intervention group, 27 (26.21\%) patients had a suspected ADE out of a total of 35 events. This number was significantly lower in the intervention group, which had 18 events in eleven $(10.37 \%)$ patients $(P<0.001)$. When the preventability of events was evaluated, 19 events were possibly preventable in the no-intervention group vs five in the intervention group $(P=0.03)$. The major cause of preventable events was overdose, which resulted in 17 preventable events in the no-intervention group and three in the intervention group. Regarding the seriousness of events, the majority

Table 5 Comparison of adverse drug events between the nointervention group and the intervention group

\begin{tabular}{|c|c|c|c|}
\hline Parameter & $\begin{array}{l}\text { No-intervention } \\
\text { n (\%) }\end{array}$ & $\begin{array}{l}\text { Intervention } \\
\mathrm{n}(\%)\end{array}$ & $P$ value \\
\hline \multicolumn{4}{|l|}{ Preventability } \\
\hline Preventable & $19(54.28)$ & $5(27.77)$ & 0.03 \\
\hline Unpreventable & I6 (45.7I) & $13(72.22)$ & 0.18 \\
\hline \multicolumn{4}{|l|}{ Causality } \\
\hline Highly & I5 (42.86) & $5(27.78)$ & 0.02 \\
\hline Probable & II (3I.43) & 7 (38.89) & 0.26 \\
\hline Possible & $9(25.7 \mathrm{I})$ & $6(33.33)$ & 0.21 \\
\hline \multicolumn{4}{|l|}{ Seriousness } \\
\hline Serious & $7(20.00)$ & $3(16.67)$ & 0.11 \\
\hline Significant & $17(48.57)$ & $8(44.44)$ & 0.02 \\
\hline Insignificant & II (3I.43) & 7 (38.89) & 0.19 \\
\hline \multicolumn{4}{|c|}{ Main drug class related ADEs } \\
\hline Antibiotics & $12(34.29)$ & $6(33.33)$ & 0.03 \\
\hline Electrolytes & $9(25.7 \mathrm{I})$ & $4(22.22)$ & 0.28 \\
\hline Cardiovascular drugs & $6(17.14)$ & $3(16.67)$ & 0.19 \\
\hline Sedatives & $3(8.57)$ & $3(16.67)$ & 0.68 \\
\hline Others & $5(14.29)$ & $2(11.11)$ & 0.16 \\
\hline Total & $35(100)$ & $18(100)$ & $<0.001$ \\
\hline
\end{tabular}

Abbreviations: $A D E$, adverse drug event; $n$, number. 
of identified ADEs caused significant injury (48.6\% in the preintervention period and $44.4 \%$ in the postintervention period) to the patients involved; the number of these ADEs differed significantly between the two study groups $(P=0.02)$. Examples of serious ADEs included generalized convulsion by cefepime overdose, intestinal bleeding caused by heparin, and frequent ventricular premature beats by toxic digoxin. Antibiotics were the first medications to cause ADEs, $12(34.29 \%)$ in the no-intervention group and six $(33.33 \%)$ in the intervention group $(P=0.03)$.

\section{Discussion}

Since the available literature on the removal of individual drugs through CRRT is limited, correct drug dosing in ICU patients receiving CRRT is difficult. Also, the results cannot be generalized because of the wide variation in CRRT techniques and settings and the heterogeneity of the patient population. ${ }^{16,17}$ The clinical situation for critically ill patients may also rapidly change over time. Therefore, drug dosing in patients receiving CRRT should be individualized. Engaging the services of a pharmacist who specializes in drug dosing monitoring for patients receiving CRRT may improve drug dosing errors and subsequent outcomes.

The evaluation of pharmacist dosing adjustment is based on several important factors. The pharmacist made 233 dosing optimizing recommendations in the intervention group, among which $90.98 \%$ were accepted by physicians. Our results concurred with several studies indicating that pharmacists are well recognized as a crucial member in a multidisciplinary ICU team, due to the complementary pharmacotherapeutic knowledge provided by clinical pharmacists. ${ }^{18,19}$ The most common dosing adjustment recommendation that occurred in this study was related to changes in CRRT length per day. Other common reasons for dosing adjustment recommendations included changes to the CRRT mode or the ultrafiltrate rate, switching CRRT to IHD/PD, or CRRT discontinuation. The variables affecting drug elimination during CRRT for critically ill patients with renal failure can be broadly divided into three categories: patientrelated variables, CRRT-related variables, and drug-related variables. ${ }^{11}$ Our results demonstrated that changes in CRRTrelated variables $(144,61.81 \%)$ during a patient's ICU stay were the most common risk factors for dosing errors.

Table 3 shows that antibiotics were associated with the highest rate of dosing errors. One reason for this finding is that the majority of critically ill patients receiving CRRT might experience complications of infections and thus require antibiotics. Another very important reason is that antibiotics such as beta-lactams and glycopeptides are primarily cleared by the kidneys and may undergo substantial removal during CRRT. Thus, dosing adjustments are frequently required, but appropriate dosing is infrequently achieved. If the renal clearance of a drug is normally less than $25 \%-30 \%$ of the total body clearance, drug removal by CRRT slightly influences the total body clearance and dosing adjustments need not be considered. ${ }^{4}$ However, members of the ICU medical team still made $27.90 \%$ dosing errors on medications that do not require dosing adjustments; these errors were possibly associated with the physicians being unfamiliar with the pharmacokinetics of the prescribed medications. The involvement of a pharmacist with the medical team may help the team to better understand the prescribed medications.

It is reported that critically ill patients with kidney injury were 13 times more likely to have an ADE. ${ }^{19}$ That the participation of pharmacists in clinical rounds may lower the frequency of ADEs is evidenced by several studies. ${ }^{18,20,21}$ Similar results were found in this study; the presence of a pharmacist for dosing adjustment of critically ill patients with CRRT reduced the incidence of ADEs by 1.94 times. ADEs detected in the intervention group are possibly related with overdose events that happened when the pharmacists were absent, whereas the higher rate of drug overdoses in the no-intervention group are possibly related to drug doses remaining unchanged when changes to the CRRT treatment warranted adjustments.

Pharmacist dosing adjustments could also lead to cost savings for patients receiving CRRT. Our results indicated that ICU pharmacists can produce savings of about $\$ 2,345.98$ per critical patient receiving CRRT, and could probably lead to a total savings of around $\$ 490,309.82$ in 1 year. The pharmacist cost savings for a patient receiving CRRT may constitute two main portions. First, some of the drugs prescribed were expensive, and dosage adjustment led to substantial savings. These drugs included imipenem/cilastatin, meropenem, piperacillin/tazobactam, cefepime, and fluconazole. Second, optimized dosing for an ICU patient receiving CRRT may reduce or prevent extra costs resulting from drug therapy failure and ADEs, namely extra drug acquisition, laboratory tests, medical materials, and nursing time. Although a number of studies have reported actual values corresponding to critical care pharmacist cost savings, ${ }^{22-24}$ those pertaining to patients receiving CRRT are limited.

This study has several limitations. The design (no-intervention and intervention phase) is clearly not as robust as a randomized prospective trial, and therefore could be biased by a number of causes. However, major 
potential confounding factors that may affect the outcomes, such as the severity of illness, length of CRRT, and the number of drugs used in the ICU, were compared between the no-intervention and intervention groups. No significant difference was found in terms of APACHE II scores, renal function, length of CRRT, and number of drugs used in the ICU. The second limitation was there may have been some disparity in the way that the ADEs were assessed; to minimize this difference, the same couple of reviewers, who were blinded to the patients' allocation, were consulted during ADE assessment. Finally, the economic results in this study were obtained from an ICU based on the Chinese medical system. Costs and savings may differ among the institution or region, and may be an additional limitation of this study.

\section{Conclusion}

This study demonstrated that changes in CRRT-related variables during a patient's ICU hospitalization are the most common risk factors for CRRT drug dosing errors. The inclusion of a pharmacist who specializes in dosing adjustment for patients receiving CRRT is well accepted by physicians, and is associated with lower ADE rates and cost savings. These results may support the development of strategies to optimize drug dosing in patients receiving CRRT.

\section{Acknowledgments}

This work was sponsored by National Nature Science Foundation of China under contracts 81301611 and 81121002 and the public health scientific research fund of the China Ministry of Health under contract 201002021.

\section{Disclosure}

The authors report no conflicts of interest in this work.

\section{References}

1. Joy MS, Matzke GR, Armstrong DK, Marx MA, Zarowitz BJ. A primer on continuous renal replacement therapy for critically ill patients. Ann Pharmacother. 1998;32(3):362-375.

2. Trotman RL, Williamson JC, Shoemaker DM, Salzer WL. Antibiotic dosing in critically ill adult patients receiving continuous renal replacement therapy. Clin Infect Dis. 2005;41(8):1159-1166.

3. Prowle JR, Schneider A, Bellomo R. Clinical review: Optimal dose of continuous renal replacement therapy in acute kidney injury. Crit Care. 2011;15(2):207.

4. Bugge JF. Pharmacokinetics and drug dosing adjustments during continuous venovenous hemofiltration or hemodiafiltration in critically ill patients. Acta Anaesthesiol Scand. 2001;45(8):929-934.
5. González de Molina FJ, Ferrer R. Appropriate antibiotic dosing in severe sepsis and acute renal failure: factors to consider. Crit Care. 2011;15(4):175.

6. Choi G, Gomersall CD, Tian Q, Joynt GM, Li AM, Lipman J. Principles of antibacterial dosing in continuous renal replacement therapy. Blood Purif. 2010;30(3):195-212.

7. Seyler L, Cotton F, Taccone FS, et al. Recommended $\beta$-lactam regimens are inadequate in septic patients treated with continuous renal replacement therapy. Crit Care. 2011;15(3):R137.

8. Churchwell MD, Mueller BA. Drug dosing during continuous renal replacement therapy. Semin Dial. 2009;22(2):185-188.

9. Thompson AJ. Drug dosing during continuous renal replacement therapies. J Pediatr Pharmacol Ther. 2008;13(2):99-113.

10. Matzke GR, Aronoff GR, Atkinson AJ Jr, Bennett WM, Decker BS, Eckardt KU, et al. Drug dosing consideration in patients with acute and chronic kidney disease-a clinical update from Kidney Disease: Improving Global Outcomes (KDIGO). Kidney Int. 2011;80(11):1122-1137.

11. Glossop A, Seidel J. Dosing regimes for antimicrobials during continuous veno-venous haemofiltration (CVVH). J Intensive Care Soc. 2008;9(2):160-165.

12. Gavaza P, Brown CM, Lawson KA, Rascati KL, Steinhardt M, Wilson JP. Pharmacist reporting of serious adverse drug events to the Food and Drug Administration. J Am Pharm Assoc (2003). 2012;52(5): e109-e112.

13. Nebeker JR, Barach P, Samore MH. Clarifying adverse drug events: a clinician's guide to terminology, documentation, and reporting. Ann Intern Med. 2004;140(10):795-801.

14. Nebeker JR, Hurdle JF, Hoffman J, Roth B, Weir CR, Samore MH. Developing a taxonomy for research in adverse drug events: potholes and signposts. Proc AMIA Symp. 2001:493-497.

15. Park SK, Chun HJ, Kim DW, Im TH, Hong HJ, Yi HJ. Acute Physiology and Chronic Health Evaluation II and Simplified Acute Physiology Score II in predicting hospital mortality of neurosurgical intensive care unit patients. J Korean Med Sci. 2009;24(3):420-426.

16. Schetz M. Drug dosing in continuous renal replacement therapy: general rules. Curr Opin Crit Care. 2007;13(6):645-651.

17. Roberts DM, Roberts JA, Roberts MS, et al; RENAL Replacement Therapy Study Investigators. Variability of antibiotic concentrations in critically ill patients receiving continuous renal replacement therapy: a multicentre pharmacokinetic study. Crit Care Med. 2012;40(5): 1523-1528.

18. Montazeri M, Cook DJ. Impact of a clinical pharmacist in a multidisciplinary intensive care unit. Crit Care Med. 1994;22(6): 1044-1048.

19. Kane-Gill SL, Kirisci L, Verrico MM, Rothschild JM. Analysis of risk factors for adverse drug events in critically ill patients*. Crit Care Med. 2012;40(3):823-828.

20. Kucukarslan SN, Peters M, Mlynarek M, Nafziger DA. Pharmacists on rounding teams reduce preventable adverse drug events in hospital general medicine units. Arch Intern Med. 2003;163(17):2014-2018.

21. Mergenhagen KA, Blum SS, Kugler A, et al. Pharmacist- versus physician-initiated admission medication reconciliation: impact on adverse drug events. Am J Geriatr Pharmacother. 2012;10(4):242-250.

22. Kopp BJ, Mrsan M, Erstad BL, Duby JJ. Cost implications of and potential adverse events prevented by interventions of a critical care pharmacist. Am J Health Syst Pharm. 2007;64(23):2483-2487.

23. Klopotowska JE, Kuiper R, van Kan HJ, et al. On-ward participation of a hospital pharmacist in a Dutch intensive care unit reduces prescribing errors and related patient harm: an intervention study. Crit Care. 2010;14(5):R174.

24. Kane SL, Weber RJ, Dasta JF. The impact of critical care pharmacists on enhancing patient outcomes. Intensive Care Med. 2003;29(5): 691-698. 


\section{Publish your work in this journal}

Therapeutics and Clinical Risk Management is an international, peerreviewed journal of clinical therapeutics and risk management, focusing on concise rapid reporting of clinical studies in all therapeutic areas, outcomes, safety, and programs for the effective, safe, and sustained use of medicines. This journal is indexed on PubMed Central, CAS,

EMBase, Scopus and the Elsevier Bibliographic databases. The manuscript management system is completely online and includes a very quick and fair peer-review system, which is all easy to use. Visit http://www.dovepress.com/testimonials.php to read real quotes from published authors.

Submit your manuscript here: http://www.dovepress.com/therapeutics-and-clinical-risk-management-journal 